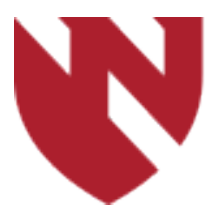

October 2021

\title{
General Anesthesia... Hold the Volatile and Propofol, Please!
}

\author{
Mackenzie S. Laurila \\ University of Nebraska Medical Center \\ Kunal Sualy \\ University of Nebraska Medical Center
}

Tell us how you used this information in this short survey.

Follow this and additional works at: https://digitalcommons.unmc.edu/gmerj

Part of the Higher Education Commons, and the Medicine and Health Sciences Commons

\section{Recommended Citation}

Laurila, M. S., , Sualy, K. General Anesthesia... Hold the Volatile and Propofol, Please!. Graduate Medical Education Research Journal. 2021 Oct 04; 3(1).

https://digitalcommons.unmc.edu/gmerj/vol3/iss1/44

This Conference Proceeding is brought to you for free and open access by DigitalCommons@UNMC. It has been accepted for inclusion in Graduate Medical Education Research Journal by an authorized editor of DigitalCommons@UNMC.For more information, please contact digitalcommons@unmc.edu. 
General Anesthesia... Hold the Volatile and Propofol, Please!

Creative Commons License

(C) $(\mathbb{\theta} \Theta \Theta$

This work is licensed under a Creative Commons Attribution-Noncommercial-No Derivative Works 4.0 License. 


\section{General Anesthesia... Hold the Volatile and Propofol, Please!} Mackenzie S. Laurila ${ }^{1,2}$, Kunal Sualy, ${ }^{1,2}$

${ }^{1}$ University of Nebraska Medical Center, College of Medicine, Department of Anesthesiology ${ }^{2}$ Children's Hospital and Medical Center, Department of Anesthesiology

Mentor: Kunal Sualy

Program: Pediatric Anesthesiology

Type: Case Report

Background: The DEGS1 gene encodes a protein located in the endoplasmic reticulum. Mutations are associated with a sphingolipid imbalance, leading to hypomyelination, degeneration of central and peripheral nervous systems, and ultimately leukodystrophy. This is considered a mitochondrial myopathy. Features include motor arrest, nystagmus, spasticity, and failure to thrive. There is variability in disease severity due to "heteroplasmy" of mutant to normal mitochondrial DNA in affected tissues. Propofol depresses mitochondrial function, and increases the risk of developing lactic acidosis, and is therefore avoided. There is no association with malignant hyperthermia. Our case presented a rare instance in which the patient had a mitochondrial disorder, as well as a family history of malignant hyperthermia. This combination limited commonly used anesthetics, namely volatile agents and propofol.

Case: An 8-year-old, $30.4 \mathrm{~kg}$ male with neuromuscular scoliosis presented for a T2 to pelvis posterior spinal fusion. Medical history included DEGS1 mutation with associated leukodystrophy, spastic quadriplegia, seizures, developmental delay, hypotonia, dysphagia, gastrostomy tube dependence, hypothyroidism, and a family history of malignant hyperthermia (maternal grandfather). Consent for surgery, anesthesia, and involvement in a case report was obtained from his parents.
Conclusion: The patient was induced with midazolam, fentanyl, ketamine, and rocuronium. After airway securement, a radial arterial line and central venous catheter were placed. Anesthesia was maintained with versed, remifentanil, and ketamine infusions. The patient received one unit of packed red blood cells, one unit of fresh frozen plasma, $420 \mathrm{~mL}$ of cell-saver, and $1500 \mathrm{~mL}$ crystalloid. He was transported to the PICU intubated and sedated and was successfully extubated on post-operative day one.

https://doi.org/10.32873/unmc.dc.gmerj.3.1.029

\section{Traumatic Optic Neuropathy and Cerebrospinal Fluid Leak: A Case Report} Adam B. Robinson ${ }^{1}$, Jason B. Untrauer ${ }^{1}$

${ }^{1}$ University of Nebraska Medical Center, College of Medicine, Department of Surgery, Division of Oral \& Maxillofacial Surgery

Mentor: Jason B Untrauer

Program: Oral \& Maxillofacial Surgery

Type: Case Report

Background: Both cerebrospinal fluid (CSF) leaks and traumatic optic neuropathy $(\mathrm{TON})$ are rare complications in cranio-maxillofacial trauma patients, with reported rates ranging from $1-3 \%$ and $2.5-10 \%$, respectively. Both are often treated non-surgically, however, surgery still plays a role. We present a case in which both of these complications occurred in the same patient with otherwise non-operable cranio-maxillofacial fractures.

Case: A 63-year-old male fell 14 feet onto concrete, resulting in multiple minimally displaced skull and facial fractures, intracranial hemorrhages, and pneumocephalus as demonstrated by computed tomography. No loss of consciousness, changes in vision, or rhinorrhea were reported. Vision was intact initially but progressed to blindness over the ensuing 24 hours. Endoscopic optic nerve decompression was considered by ophthalmology and ENT, however, the patient was ultimately treated with $250 \mathrm{mg}$ of intravenous Solumedrol every 6 hours over a three day period. Additionally, despite 48 hours of bedrest, the patient developed significant clear rhinorrhea while standing to use the commode, suggesting a CSF leak. A provocative CSF bedside stress test confirmed a persistent leak. A lumbar drain was placed with anticipation of resolving the persistent CSF leak and avoiding intra-cranial surgery. Verbal consent obtained from patient to discuss his case for educational purposes.

Despite steroid therapy, the patient's vision loss failed to improve. The lumbar drain was successful in resolving the CSF leak, negating the need for neurosurgical intervention.
Conclusion: TON and CSF leaks are rare complications of craniofacial trauma with treatments encompassing both medical and surgical management. This case illustrates both the complexity of craniomaxillofacial fractures and the importance of a multidisciplinary approach.

https://doi.org/10.32873/unmc.dc.gmerj.3.1.022 